\title{
Study on Effect of Laser Process Parameters on Laser Transmission Weld Parameters using ANSYS
}

\author{
Girish Kumar R ${ }^{1}$, Abhay Agarwal ${ }^{2}$, Utkarsha Mohan ${ }^{3}$ and Shounak Dey ${ }^{4}$ \\ ${ }^{1}$ Asst. Professor, Dept. of Mechanical Engineering, RV College of Engineering \\ ${ }^{2}$ Dept. of Mechanical Engineering, $R V$ College of Engineering \\ ${ }^{3}$ Dept. of Mechanical Engineering, $R V$ College of Engineering \\ ${ }^{4}$ Dept. of Mechanical Engineering, $R V$ College of Engineering \\ 1girishkumarr@rvce.edu.in,2abhayagarwal.me17@rvce.edu.in, \\ ${ }^{3}$ utkarshamohan.me17@rvce.edu.in, ${ }^{4}$ shounakdey.me17@rvce.edu.in
}

\begin{abstract}
In recent years, a mode of welding that has garnered a considerable amount of interest is the laser transmission welding of thermoplastics. Laser transmission welding is now being used as an alternative to adhesives to join two thermoplastics. In this study, a finite element model has been developed to simulate the laser transmission welding of polypropylene. The movement ofthe laser beam was done using a Moving Heat Source in Ansys ${ }^{\circledR}$. Process parameters namely laser power, welding speed and the number of passes have been studied in order to investigate their effects on the temperatures and the weld widths achieved during welding. It was found that increase in the laser power had a positive effect on the maximum temperature at weld interface as well as the weld width. Similarly, increase in the welding speed had a negative influence on the maximum temperature at weld interface as well as the weld width.
\end{abstract}

Keywords: Laser Transmission Welding, Finite Element Methods, Thermoplastics

\section{Introduction}

Plastics are being widely used all all over the world in many of the industries for manufacturing of toys, utensils, automotive parts, aerospace parts and also in medical use. Frequently plastics and their composites are used in many industries due to their low weight, low cost, good corrosion resistance, decent strength to weight ratio and ability to take good finish. In many applications different geometries and shapes are required. Also joining of plastics is required and the thermoplastics can be softened and remolded by means of heating and can fusion welded. A part from mechanical fastening and adhesive bonding many other joining techniques can be used such as a. Thermal welding b. Friction welding and c. Electromagnetic welding. Further the thermal plastic welding is classified as a. Hot air welding b. Hot tool welding c. Laser beam heating and d. Infrared heating [1] [2]

The traditional methods of joining two plastics include ultrasonic welding, cementing and sweat soldering. The traditional methods are not completely environment friendly and have their own shortcomings. The method of cementing does not offer good joint strength and reliability while a toxic gas is produced in sweat soldering and the material is subjected to high welding stress in the case of ultrasonic welding[3]. Therefore, this makes it necessary to develop alternative methods yielding high joint strength and at the same time being cost effective. Laser transmission welding is highly précised as the laser movement can be controlled accurately. It is also a non-contact method of joining which reduces mechanical loads on the material. In addition to this, the process is flexible, requires very short cycle times and therefore incurs a low total cost of ownership. [4] 
Laser transmission welding involves a laser transmitting and laser absorbing joined to form a lap joint generally. The bottom part is the laser absorbing while the top past is laser transmitting. The top part should be such that sufficient portion of the laser beam should be able to penetrate through to the weld interface. The laser beam energy is absorbed by the opaque part resulting in the melting of the two parts at the interface. After cooling and solidification, a firm and aesthetic weld seam is produced at the interface[5][6]

Hopmann C. et al. [7] studied the residual stresses induced during laser transmission welding. A thermo-mechanical model was developed to simulate the laser transmission welding. The residual stresses induced in Polyamide 6.6 was calculated after cooling.

Acherjee et al. [8]studied the laser transmission welding of polycarbonate to ABS through empirical modelling. The effect of laser power, welding speed, standoff-distance and clamp pressure on weld strength, weld width were investigated through empirical models developed by response surface methodology.

D. Parkes[9] et al investigated on the use of fiber laser to join High strength low alloy (HSLA) and dual-phase DP980 with similar and dissimilar combination of material. Rise in the yield strength (YS), Ultimate tensile strength (UTS) and Energy absorption (EA) with decreasing Temperature was observed.

Furat I. Hussein et al. [10]did an experimental study on joining of dissimilar property materials, that was a combination of transparent Polymethyl methacrylate (PMMA) and stainless steel (SS) 304 sheets using a pulsed mode Nd: YAG laser. The weld joint strength and weld seam width was found to be $925 \mathrm{~N}$ and $7.25 \mathrm{~mm}$ respectively.

Dragi Stamenkovic [11] had described the method for determination residual stresses in butt joint of two similar materials in finite element analysis by considering the numerical example and theoretical considerations.

Benoit Cosson et al. [12] introduced a ray tracing method with finite element method to study both the absorption and light-scattering caused by the heterogeneity of the material. The influence of the absorption on the heat affected zone was investigated.

\section{Methodology}

For this study, the material identified after conducting literature survey was polypropylene, two pieces of which were taken, one opaque (black) and the other one being transparent. The dimensions of the pieces were taken to be $80 \times 35 \times 4 \mathrm{~mm}$, with the overlap distance being 20 mm lengthwise, as shown in Fig 1, which were designed using ANSYS. The parameters chosen to evaluate the weld stresses are number of passes of the laser beam across the weld region indicated on the sample, variation of the power and the number of laser beam passes.

For the simulation, ADAPTIVE meshing has been chosen as the preferred method. Since the entire simulation is focused on the weld zone, in order to get the best possible accuracy, fine meshing is done in the heat affected zone and coarse meshing has been done on the remaining parts of the model. The model in total contains 207100 nodes and 45008 elements.For the simulation of the laser beam, moving heat source plug-in has been utilized by considering the adjacent body as reference with particular path and with particular starting point. 


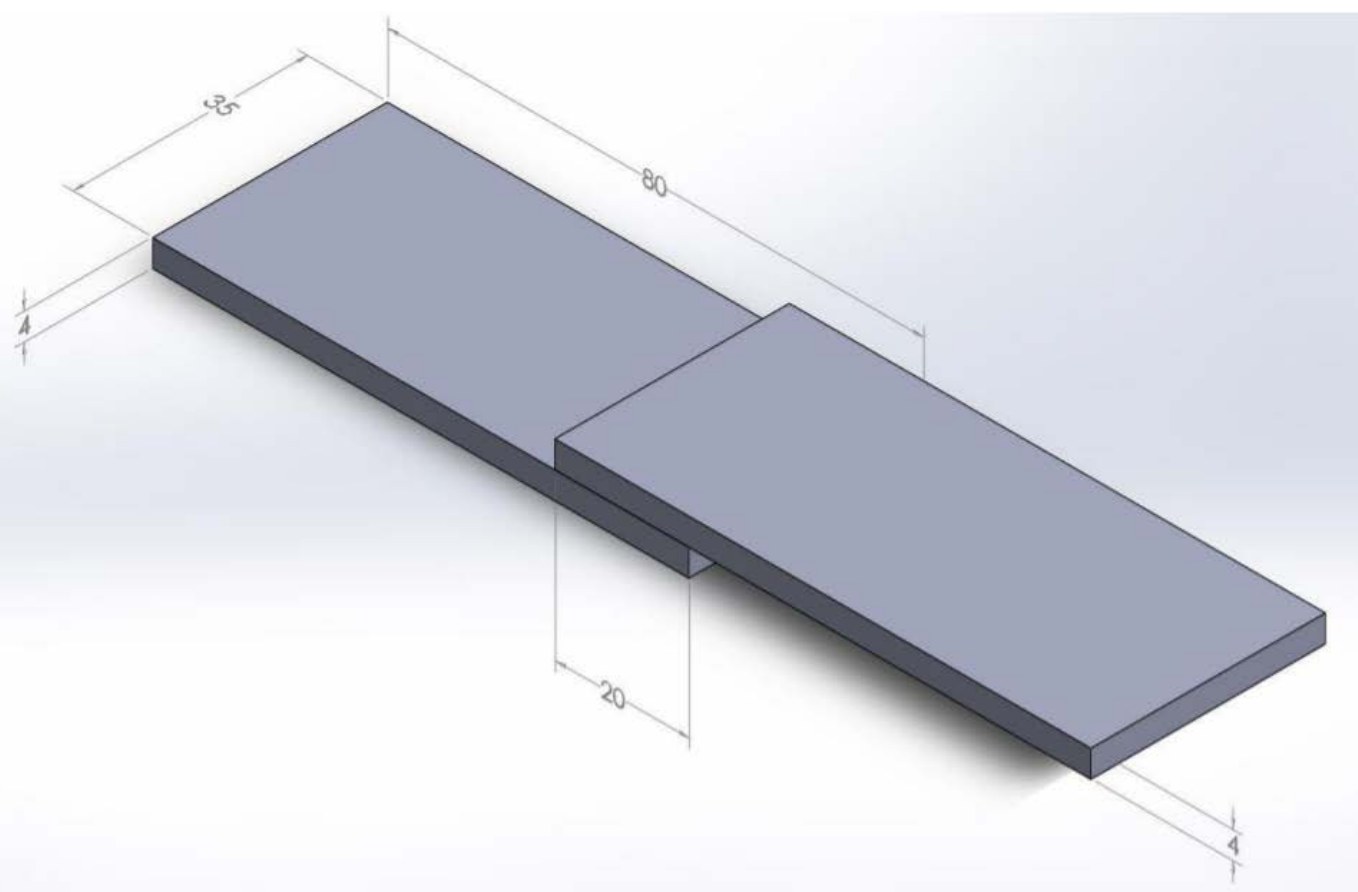

Fig 1: Lap Joint Configuration of the Weld Specimens

For the simulation, ADAPTIVE meshing has been chosen as the preferred method. Since the entire simulation is focused on the weld zone, in order to get the best possible accuracy, fine meshing is done in the heat affected zone and coarse meshing has been done on the remaining parts of the model. The model in total contains 207100 nodes and 45008 elements.For the simulation of the laser beam, moving heat source plug-in has been utilized by considering the adjacent body as reference with particular path and with particular starting point.

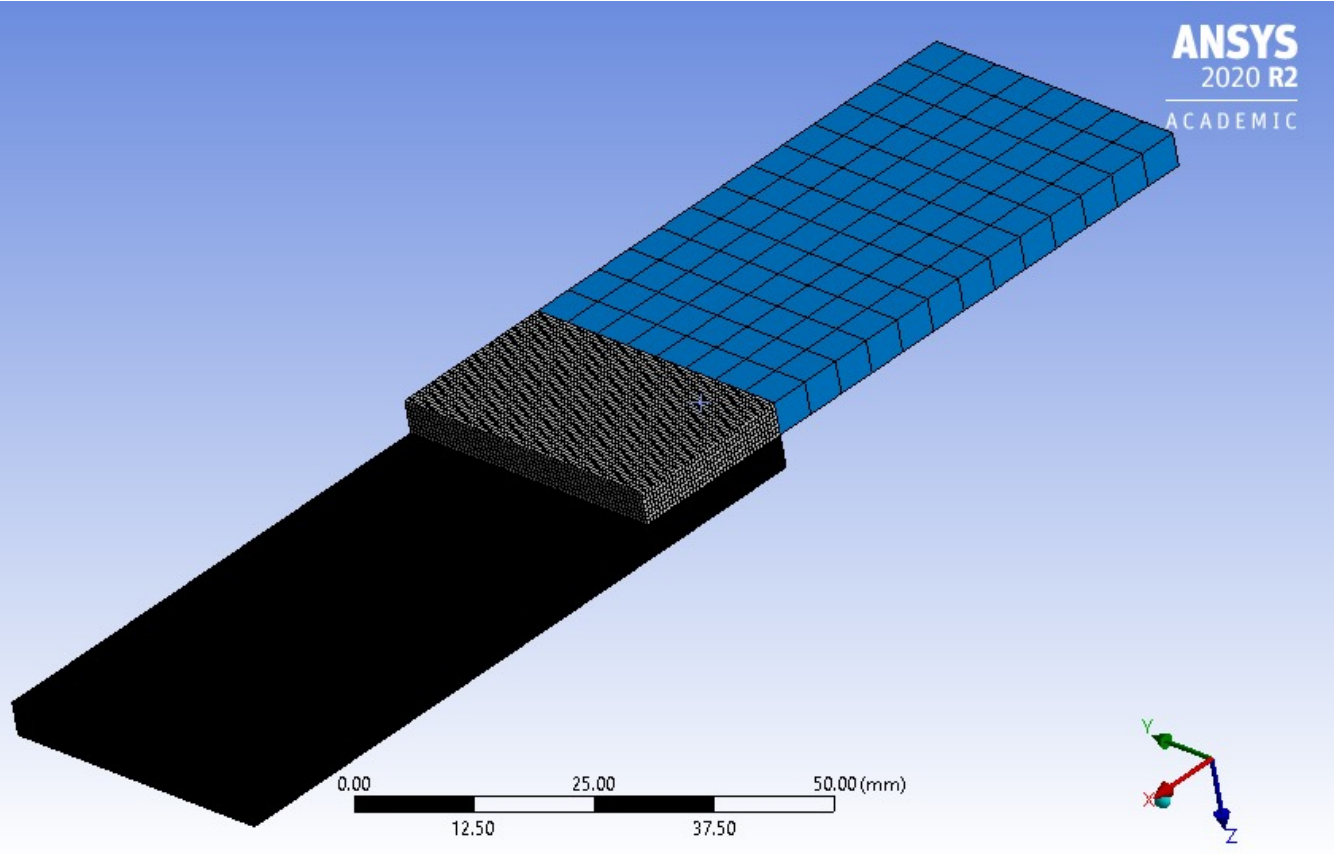

Fig 2: Polypropylene Model with Adaptive Meshing 


\section{Results and Discussions}

As the laser power increases, there is an increase in the maximum temperature at the weld interface and the weld width for constant number of passes and weld speed. This increase in maximum temperature at weld interface with an increase in input power is due to the fact that with an increased laser power, higher heat input is given to the weld interface which resultsin a higher temperature. An increase in power also led to an increase in the heat input to the weld interface resulting in more molten material and consequently greater weld dimensions were achieved. (Fig3and 4).

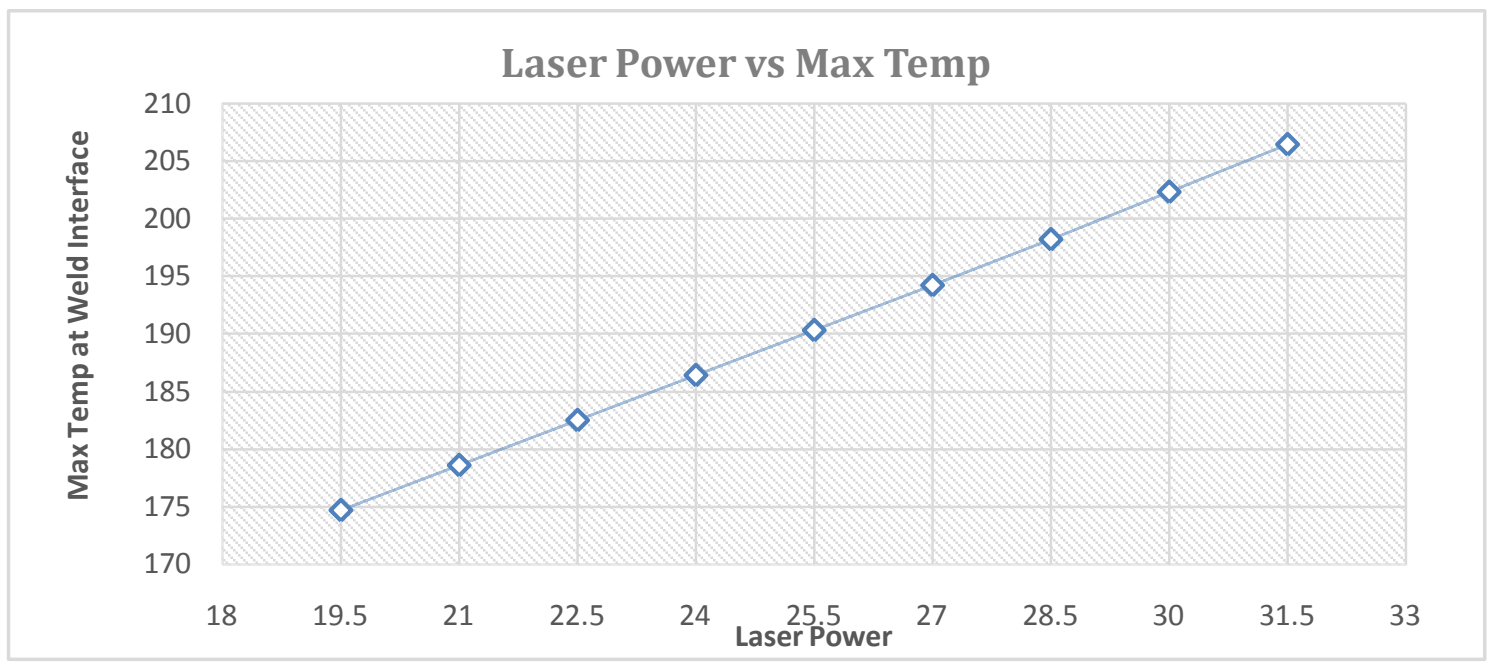

Fig3: Laser Power vs Maximum Temperature

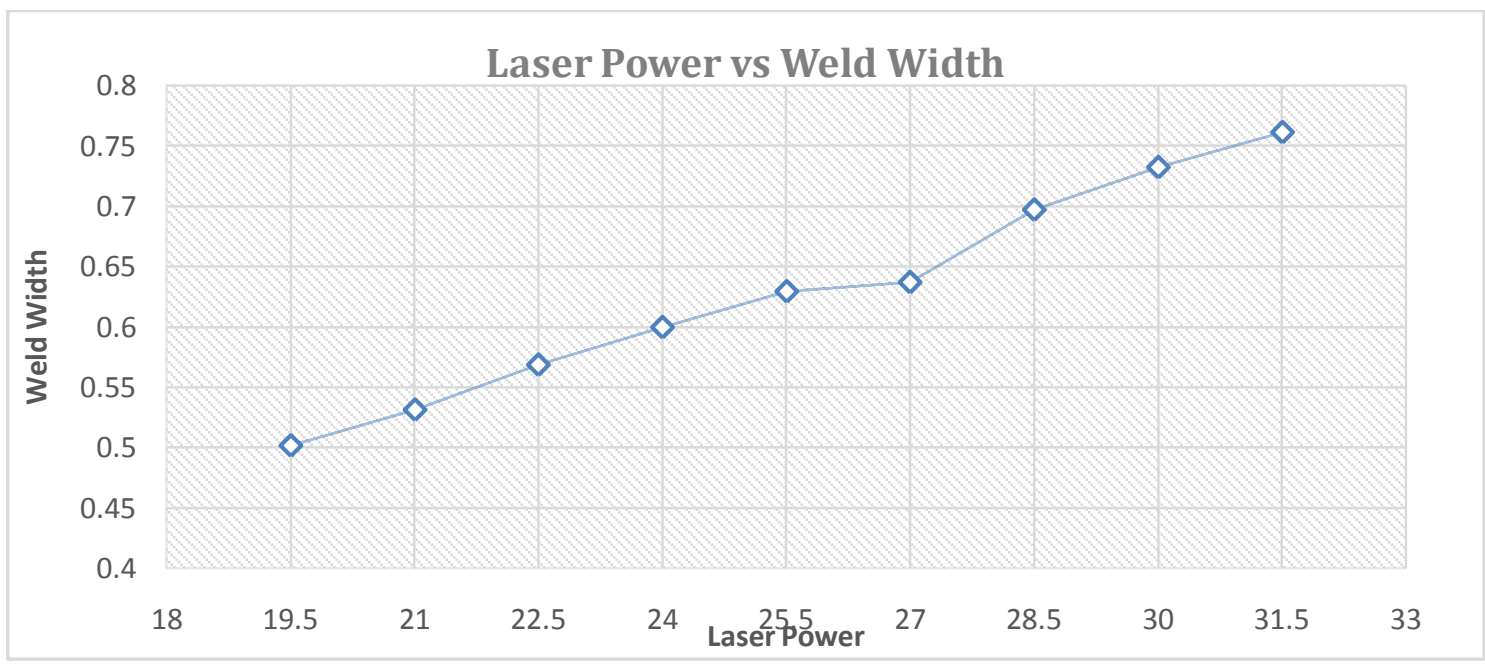

Fig 4: Laser Power vs Weld Width 
As the welding speed increases, there is a decrease in the maximum temperature at the weld interface and the weld width for constant number of passes and laser power. Decrease in the welding speed increases the time taken by the laser beam to move across the weld seam path. Due to this, the weld seam is exposed to the laser beam for larger durations and more heat is input to the interface. As more heat is input to the weld interface, a higher temperature is attained at the weld interface at lower welding speeds. Weld seam being exposed to the laser beam for larger duration at slower weld speeds also results in larger weld widths at lower welding speeds (Fig 5 and 6)

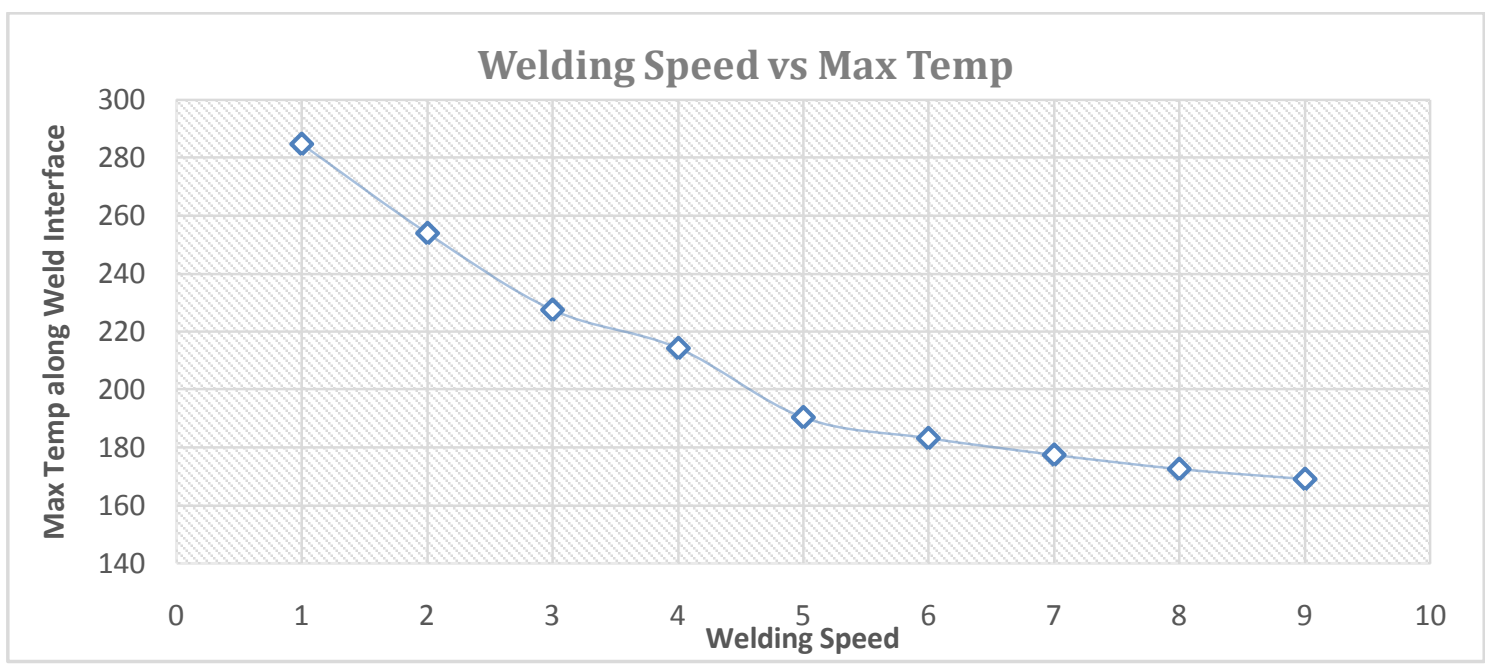

Fig 5: Welding Speed vs Max Temp for constant Laser Power (25.5W) and Number of Passes (15)

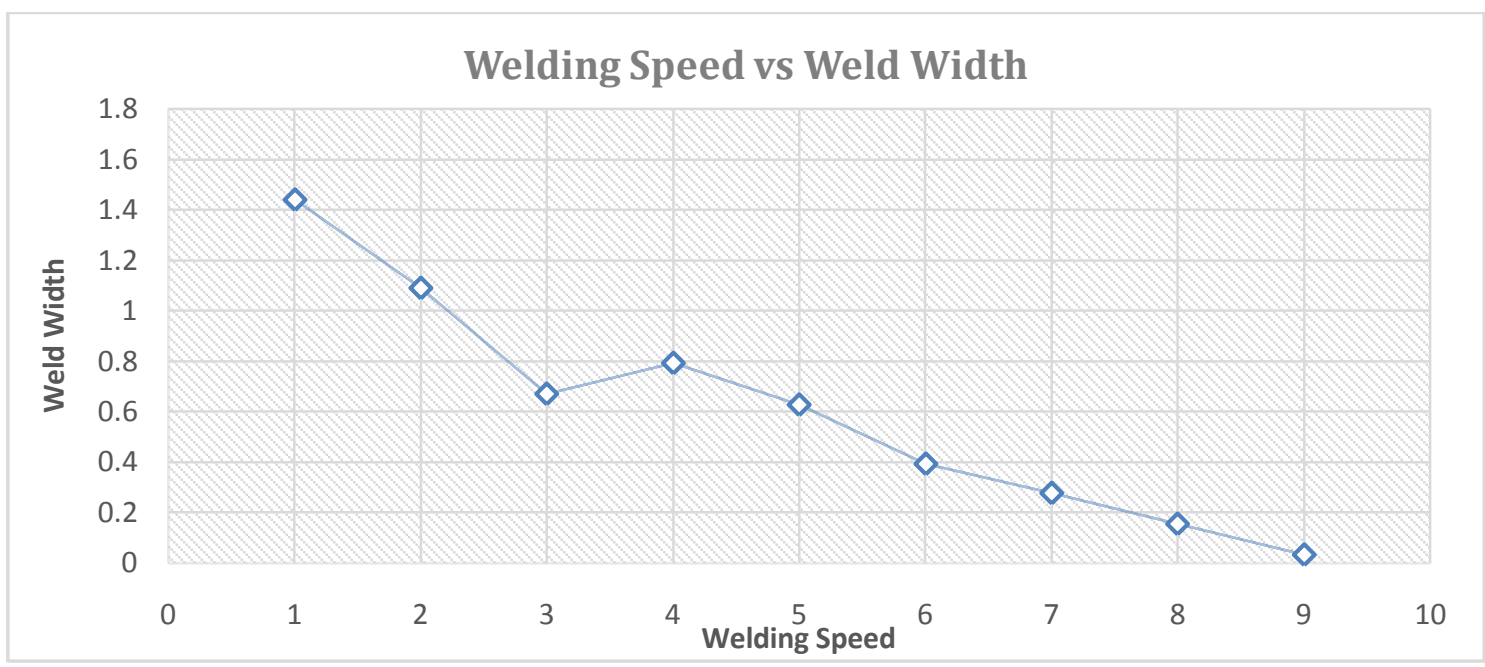

Fig 6: Welding Speed vs Weld Width for constant Laser Power (25.5W) and Number of Passes (15) 
As the number of passes increases, there is an increase in the maximum temperature at the weld interface and the weld width for constant laser power and weld speed. When all other laser welding parameters are fixed, the fast and repetitive thermal cycles result in greater laser - material interaction time, therefore higher energy per unit length is input to the interface. Due to the higher energy input, higher maximum temperatures at weld interface are achieved with increase in the number of scans. It should also be noted that the number of scans should be limited such that the maximum temperature achieved remains below the degradation temperature of the plastic.The higher temperature also results in more molten material which leads to higher weld dimensions. (Fig 7 and 8)

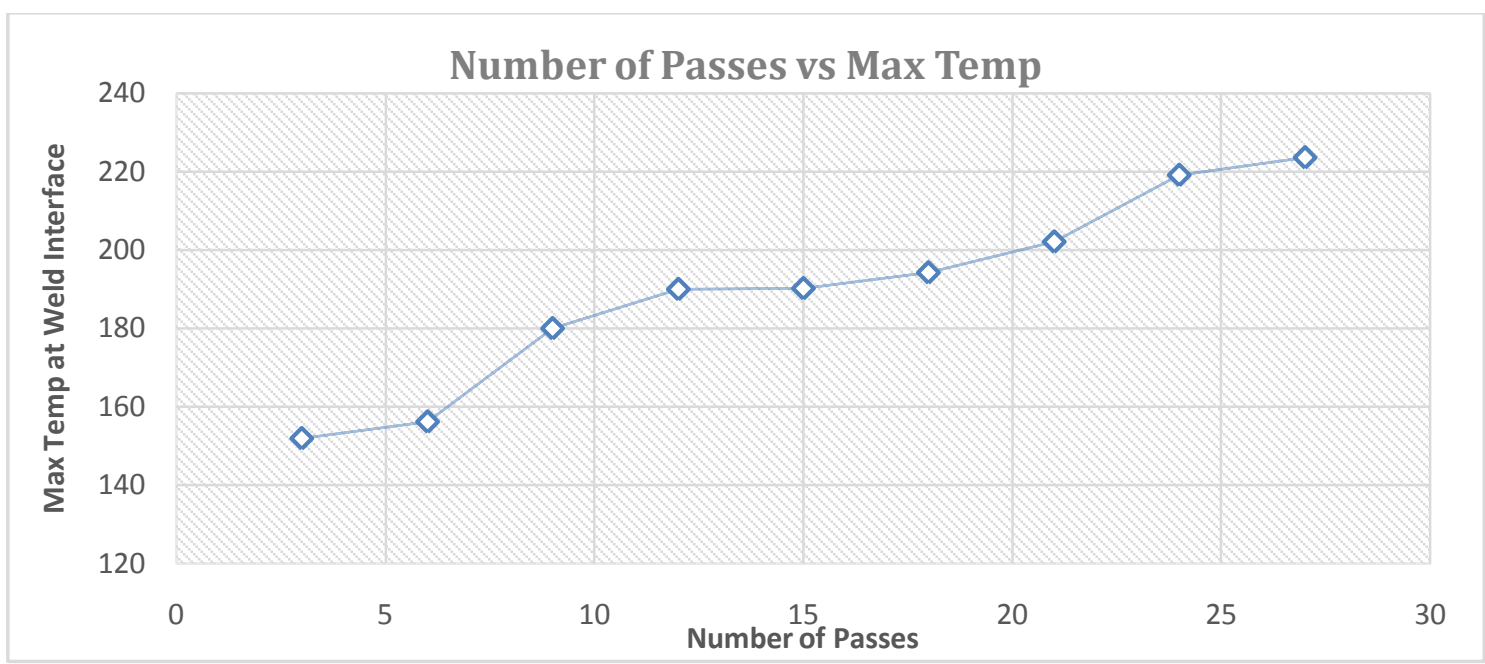

Fig7: Number of Passes vs Max Temp for constant Laser Power (25.5W) and Welding Speed $(5 \mathrm{~mm} / \mathrm{s})$

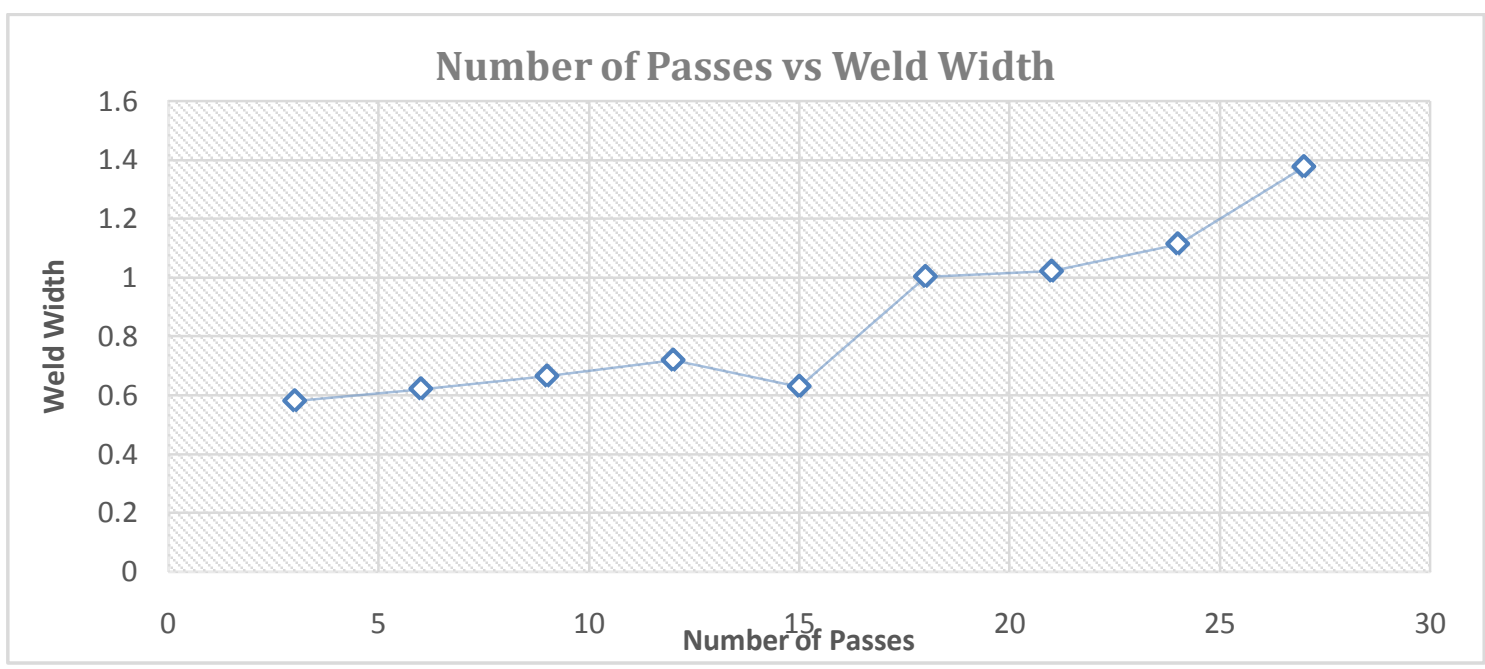

Fig8: Number of Passes vs Weld Width for constant Laser Power (25.5W) and Welding 
Fig 9represents the history of the temperature distribution along the weld seam during the course of the laser welding. From the figure, it can be observed that the temperature at any of the selected point in the weld seam sees a significant or a rapid rise as the laser beam approaches the corresponding point for every scan of the weld. This can be attributed to the very low thermal conductivity of the plastic and a significantly small time-interval between two consecutive scans. As a result of this, the observed drop in temperature is lesser when compared with the corresponding rise in temperature during each scan. The accumulation of these residual temperatures results in an overall increase in the temperature with an increase in the number of scans.

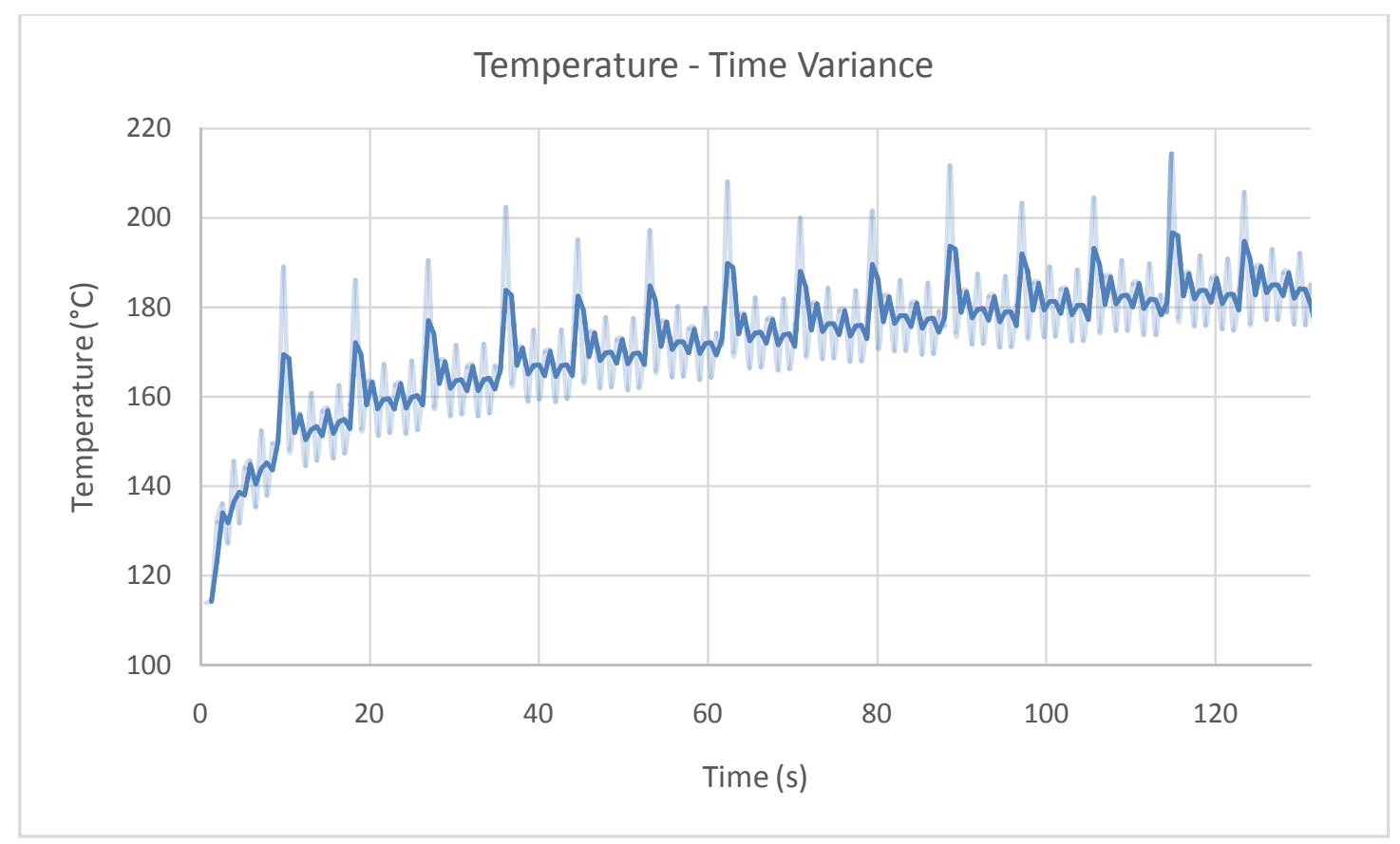

Fig9: Variation of Temperature across the Weld Seam with Time

\section{Conclusions}

The present work simulates the laser transmission welding of Polypropylene in 27 different cases, and studies the effect of the three input parameters, namely the Laser Power, Welding Speed and Number of Passes on the Maximum Weld Temperature obtained and the Weld Widths. This work may be further expanded to include more input and output factors and by using concepts of Experiment Design, an optimized case for laser welding of polypropylene may be found.

\section{Acknowledgements}

The authors wish to thank their research guide and their families for their support and guidance during the course of this research. 


\section{Bibliography}

[1] M. S. Haque and M. A. Siddiqui, "Plastic Welding: Important Facts and Development," American Journal of Mechanical and Industrial Engineering, vol. 1, no. 2, pp. 15-19, 2016.

[2] D. Grewell and A. Benatar, "Welding of plastics: Fundamentals and New Developments,” International Polymer Processing, vol. 22, pp. 43-60, 2007.

[3] Z. Chen , Y. Huang, F. Han and D. Tang, "Numerical and experimental investigation on laser transmission welding of fiberglass-doped PP and ABS," Journal of Manufacturing Processes, vol. 31, pp. 1-8, 2018.

[4] B. Acharjee, A. S. Kuar, S. Mitra and D. Misra, "Laser Transmission Welding of Thermoplastics: An Overview of Experimental Findings - Process, Development and Applications,” Journal of Manufacturing Technology Research, vol. 3, p. 26, 2011.

[5] B. Acharjee, A. Kuar, S. Mitra and D. Misra, "Laser Transmission Welding: A novel technique in Plastic Joining,” Welding: Processes, Quality and Applications, pp. 365387, 2011.

[6] F. G. Bachmann and U. A. Russek, "Laser welding of polymers using high-power diode lasers," Laser Processing of Advanced Materials and Laser Microtechnologies, vol. 5121, pp. 385-398, 2003.

[7] C. Hopmann and S. Kreimeier, "Modelling the Heating Process in Simultaneous Laser Transmission Welding of Semicrystalline Polymers," Journal of Polymers, vol. 2016, p. 10, 2016.

[8] B. Acherjee, A. S. Kuar and D. Misra, "Empirical Modeling and Multi-Response Optimization of Laser Transmission Welding of Polycarbonate to ABS,” Lasers in Manufacturing and Materials Processing, pp. 103-123, 2015.

[9] D. Parkes, D. Westerbaan, S. Nayak, Y. Zhou, F. Goodwin, S. Bhole and D. L. Chen, "Tensile properties of fiber laser welded joints of high strength low alloy and dual-phase steels at warm and low temperatures,” Materials and Design, vol. 56, pp. 193-199, 2014.

[10] F. I. Hussein, E. Akman, B. Genc Oztoprak, M. Gunes, O. Gundogdu, E. Kaca, K. I. Hajim and A. Demir, "Evaluation of PMMA joining to stainless steel 304 using pulsed Nd:YAG laser,” Optics and Laser Technology, vol. 49, pp. 143-152, 2013.

[11] D. Stamenkovic, "Finite Element Analysis of Residual Stress in Butt Welding Two Similar Plates," 2012.

[12] Benoît Cosson, A. Chateau Akué Asséko, M. Lagardère and M. Dauphin, “3D modeling of thermoplastic composites laser welding process - A ray tracing method coupled with finite element method,” Optics and Laser Technology, vol. 119, 2019. 